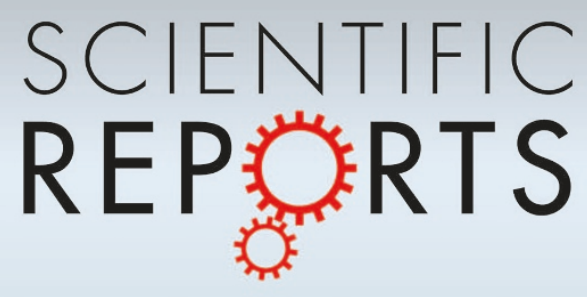

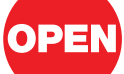

SUBJECT AREAS:

TUMOUR BIOMARKERS

RNAI

CHEMOTAXIS

EXTRACELLULAR SIGNALLING MOLECULES

Received

3 January 2013

Accepted

30 April 2013

Published

22 May 2013

Correspondence and requests for materials should be addressed to

K.K. (konstant@jhu. edu)

\section{Mesothelin Binding to CA125/MUC16 Promotes Pancreatic Cancer Cell Motility and Invasion via MMP-7 Activation}

\author{
Shih-Hsun Chen ${ }^{1,2}$, Wei-Chien Hung ${ }^{1,3}$, Pu Wang ${ }^{5}$, Colin Paul ${ }^{1,2,4}$ \& Konstantinos Konstantopoulos $1,2,3,4$
}

'Department of Chemical and Biomolecular Engineering, Johns Hopkins University, Baltimore, Maryland $21218,{ }^{2}$ Physical
Sciences-Oncology Center, Johns Hopkins University, Baltimore, Maryland $21218,{ }^{3}$ Center for Cancer Nanotechnology
Excellence, Johns Hopkins University, Baltimore, Maryland $21218,{ }^{4}$ Institute for NanoBioTechnology, Johns Hopkins University,
Baltimore, Maryland $21218,{ }^{5}$ College of Life and Health Sciences, Northeastern University, Shenyang, P. R. China 110819.

Mesothelin (MSLN) and cancer antigen125/mucin 16 (CA125/MUC16) are potential biomarkers for pancreatic cancer (PC) that are co-overexpressed at the invading edges of PC tissues, and their expression correlates with poor survival rates. However, the role of MSLN-MUC16 molecular interaction in PC cell motility and invasion has yet to be elucidated. Using sophisticated bioengineering and molecular biology tools, we report that the binding of MSLN to MUC16 markedly enhances PC cell motility and invasion via the selective induction of matrix metalloproteinase (MMP)-7. MSLN-mediated MMP-7 upregulation in MUC16-expressing PC cells occurs via a 38 MAPK-dependent pathway. Depletion of MMP-7 or inhibition of p38 activity abolishes MSLN-mediated PC motility and invasion. These findings provide a novel perspective on the enhanced invasive potential associated with MSLN and MUC16 co-overexpression, and the mechanism underlying MMP-7 activation in PC invasion and metastasis.

M esothelin (MSLN) is a 40-kDa glycosylphosphatidyl inositol (GPI)-linked protein that is natively present on mesothelial cells lining the peritoneum ${ }^{1}$. However, MSLN is highly overexpressed in various types of cancer, such as mesothelioma ${ }^{1}$, ovarian ${ }^{1}$ and pancreatic cancer $^{2,3}$, and is also detected in the sera of ovarian and pancreatic cancer patients ${ }^{4,5}$. Recent studies have demonstrated a role for MSLN in cell survival, migration, invasion and tumor progression ${ }^{6-9}$. Secreted MSLN is capable of binding to CA125/MUC16 $6^{10-12}$, which is a heavily glycosylated membrane-associated protein with molecular mass ranging from 2500 to $5000 \mathrm{kDa}^{13}$. MUC16 contains an extracellular N-terminus adjacent to O- and N-linked glycosylated tandem repeats, and a Cterminal domain consisting of a transmembrane region along with a short cytoplasmic tail ${ }^{13,14}$. MUC16 is overexpressed on the surface of ovarian ${ }^{10}$ and pancreatic ${ }^{15}$ cancer cells, but is not present in normal pancreatic ducts $^{15,16}$. MUC16 expression is strongly associated with poor survival of ovarian ${ }^{17}$ and pancreatic cancer ${ }^{15,18}$ patients. Recent immunohistological studies have shown that MUC16 and MSLN are co-expressed at the pancreatic cancer cell surface in patient tissue specimens, and the staining intensity of these two molecules is significantly higher at the invasion front than in the main tumor ${ }^{19,20}$. Furthermore, the co-expression of MUC16 and MSLN is strongly correlated with a poor prognosis and unfavorable patient outcome ${ }^{19,20}$. Although MSLN binding to MUC16 may provide adhesive capacity for metastasizing tumor cells ${ }^{10-12}$, the molecular mechanisms by which MSLN-MUC16 interaction contributes to pancreatic cancer invasion and metastasis remain largely unknown.

Matrix metalloproteinases (MMPs) play a key role in tissue remodeling and have been implicated in tumor progression and metastasis of various types of cancer including pancreatic cancer ${ }^{21}$. For instance, MMP-2, -7 , and -9 are overexpressed in pancreatic carcinoma tissues ${ }^{21-23}$. Importantly, MMP-7 expression is most pronounced at the invasive front of tumors ${ }^{21}$. MMP-7, also known as matrilysin or pump-1, has been reported as an independent prognostic factor and strongly correlates with tumor size, lymph node metastasis, and poor survival of pancreatic cancer patients ${ }^{24-26}$, whereas there is no correlation between other MMPs and survival ${ }^{21}$. Recent work suggests that MSLN overexpression promotes ovarian cancer and mesothelioma ${ }^{7,8}$ cell invasion by inducing MMP-7 or MMP-9. However, the role of MSLN in MMP regulation in pancreatic cancer has been largely overlooked. Most importantly, it is not known how the molecular interaction of MSLN and MUC16 regulates pancreatic cancer cell motility and invasion. In this study, we demonstrate that MSLN binding to MUC16 expressed by metastatic pancreatic cancer cells increases their motility and invasive potential by selectively upregulating MMP-7 via a p38 
mitogen-activated protein kinase (MAPK)-dependent pathway. Our findings suggest that co-overexpression of MSLN and MUC16 may facilitate early local invasion of pancreatic cancer cells via activation of MMP-7, and warrant further investigation into the development of therapies targeting both MSLN and MUC16 to combat pancreatic cancer metastasis.

\section{Results}

MUC16 expression correlates with pancreatic cell binding capacity to MSLN. To delineate the role of MSLN-MUC16 interaction in pancreatic cancer, we first compared the binding capacity of pancreatic cancer versus nonmalignant pancreatic epithelial cells to immobilized MSLN. To this end, three pancreatic cancer cell lines (PANC-1, SW1990, and Pa03C) and two nonmalignant pancreatic epithelial cell lines (hTERT-HPNE and HPDE) were allowed to incubate in MSLN-coated 96-well plates for 30 min under static conditions. The number of adherent SW1990 and Pa03C cells to MSLN-coated plates was $40 \%$ greater than that to BSA-coated control plates (Fig. 1A). In contrast, no difference was noted for hTERT-HPNE, HPDE, and PANC-1 cells (Fig. 1A). This differential binding capacity correlates with MUC16 surface expression. Flow cytometry reveals that MUC16 is highly expressed on the surface of metastatic SW1990 and Pa03C pancreatic cancer cells ${ }^{27}$ but is essentially absent from the nonmalignant hTERTHPNE and HPDE cells as well as PANC-1 pancreatic cancer cells (Fig. 1B). We confirmed that the increased binding of metastatic SW1990 and Pa03C cells to MSLN is MUC16-dependent, as evidenced by the use of a function-blocking anti-MUC16 monoclonal antibody $(\mathrm{mAb})^{19}$ which blocked binding to control levels (Fig. 1C). Further confirmation was provided by the use of
A

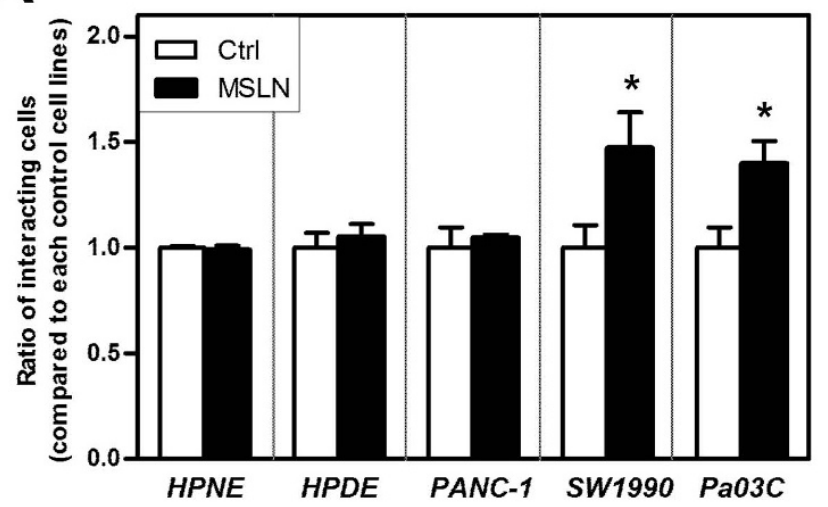

0 SW1990

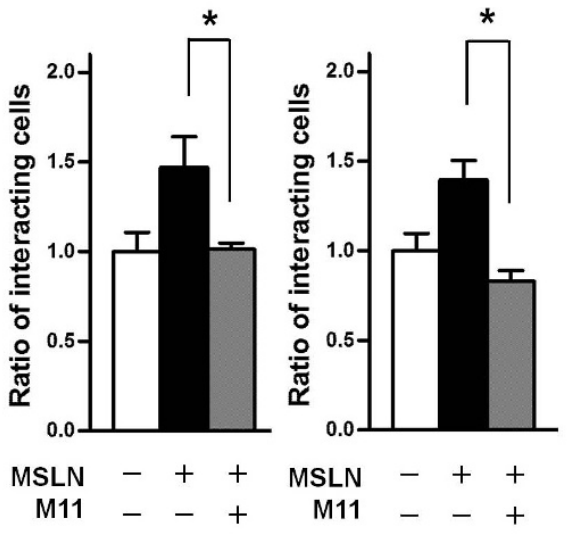

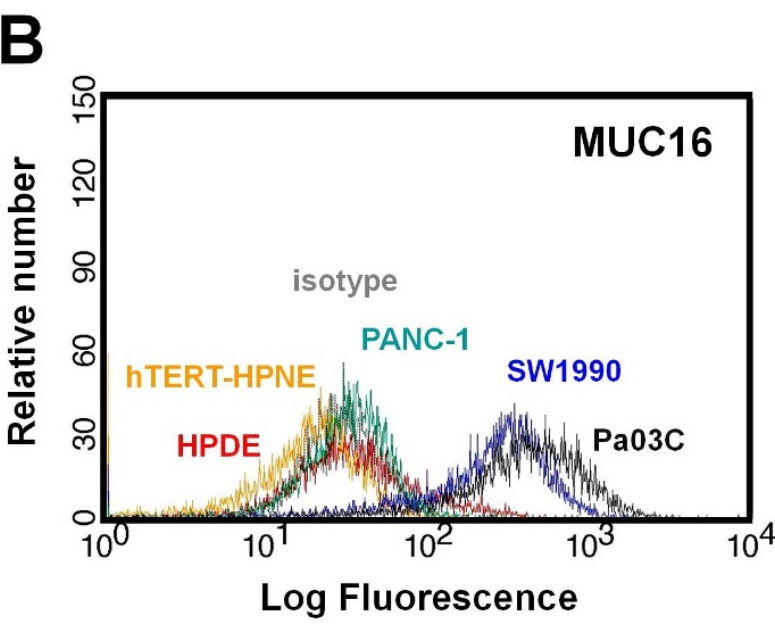

D $\underline{S W 1990}$ $\underline{P a 03 C}$

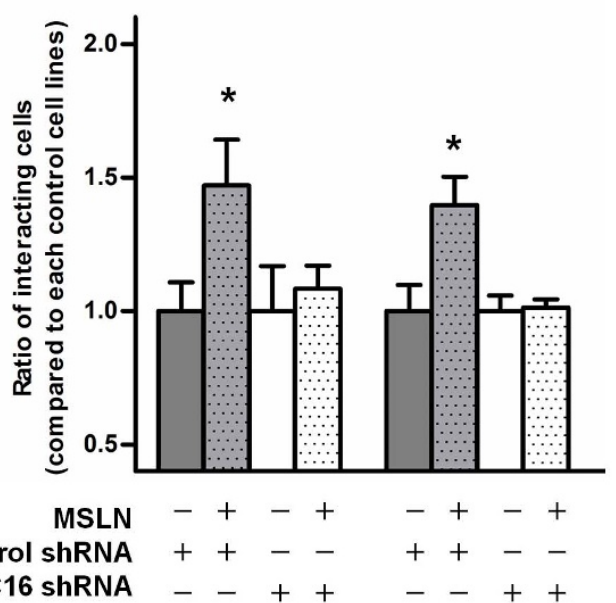

Figure 1 MUC16 expression correlates with pancreatic cancer cell binding capacity to MSLN. (A) hTERT-HPNE, HPDE, PANC-1, SW1990, and Pa03C cells were seeded in 96-well plates pre-coated with either mesothelin (MSLN) or BSA (control). After 30 min of incubation, the relative number of adherent cells to MSLN- versus BSA-coated wells was quantified by WST-1 assay. Data represent the mean \pm S.E. of three independent experiments. $*, p<0.05$ with respect to control. (B) Representative flow cytometric histograms of MUC16 surface expression on hTERT-HPNE, HPDE, PANC-1, SW1990, and Pa03C cells using indirect single-color immunofluorescence and an anti-MUC16 mAb or an isotype control. (C) MUC16-overexpressing SW1990 or Pa03C cells were pre-incubated with either a function-blocking anti-MUC16 mAb M11 (20 $\mu \mathrm{g} / \mathrm{ml})$ or an isotype control for $1 \mathrm{~h}$ at $37^{\circ} \mathrm{C}$, and then used in the cell binding assay as described in (A). (D) Scramble control or MUC16-KD SW1990 and Pa03C cells were seeded in 96-well plates pre-coated with MSLN or BSA (control). After 30 min of incubation, adherent cells were quantified by WST-1 assay. Data represent the mean \pm S.E. of three independent experiments. ${ }^{*}, p<0.05$ with respect to MUC16-KD cells. 
MUC16-knockdown (MUC16-KD) SW1990 and Pa03C cell lines ${ }^{27}$ (supplementary Fig. 1), which displayed basal levels of binding to MSLN relative to scramble control cells (Fig. 1D).

Co-immunoprecipitation assays were carried out to confirm the binding interaction between MSLN immobilized on a $15-\mathrm{cm}$ petridish and MUC16-expressing SW1990 and Pa03C cells. As shown in Fig. 2A, MSLN was detected in the immunoprecipitate fraction of MUC16 from both SW1990 and Pa03C cell lysates and vice versa. In contrast, we failed to detect MUC16 in immunoprecipitated MSLN from MUC16-KD cell lysates (Fig. 2B). Similarly, no MSLN was found in MUC16 immunoprecipitate fractions generated from MUC16-KD cell lysates (Fig. 2B).

MSLN-MUC16 interaction induces MMP-7 synthesis in pancreatic cancer cells. Previous studies have shown that MSLN may facilitate ovarian carcinoma and mesothelioma cell invasion by upregulating MMP production ${ }^{7,8}$. We thus wished to determine whether MSLN binding to MUC16 induces MMP synthesis in pancreatic cancer cells. hTERT-HPNE, HPDE, PANC-1, SW1990, and $\mathrm{Pa} 03 \mathrm{C}$ were treated with human recombinant MSLN overnight, and analyzed for expression of MMP-2, -7 , and -9 , which have been reported to be overexpressed in pancreatic cancer tissue ${ }^{21-23}$. MSLN significantly and selectively upregulated MMP-7, but not MMP-2 or -9, mRNA levels in MUC16-expressing SW1990 and Pa03C cells, as assessed by qRT-PCR (Fig. 3A-C). In contrast, MSLN failed to induce MMP-7 synthesis in hTERT-HPNE, HPDE, and PANC-1 cells (Fig. 3A), which are devoid of MUC16. Importantly, immunohistochemical analysis of tissue microarrays reveals strong immunoreactivity for MSLN, MUC16 and MMP-7 in 90\% of pancreatic cancer tissue specimens, whereas no immunostaining was detected in any of the 12 normal tissue samples (Fig. 3D).

We next examined the time- and dose-dependent effects of human recombinant MSLN on MMP-7 induction in pancreatic cancer cells. MMP-7 mRNA and protein levels increased progressively with the time of MSLN stimulation and reached a peak at $12 \mathrm{~h}$ (Fig. 4A). Moreover, maximal MMP-7 mRNA and protein levels were achieved after stimulation with $1 \mu \mathrm{g} / \mathrm{ml}$ of MSLN (Fig. 4B). Similar time- and dose-dependent trends were observed with Pa03C cells (supplementary Fig. 2A and B). The MSLN-mediated upregulation of MMP-7 in

\section{A Scramble Ctrl}

IP

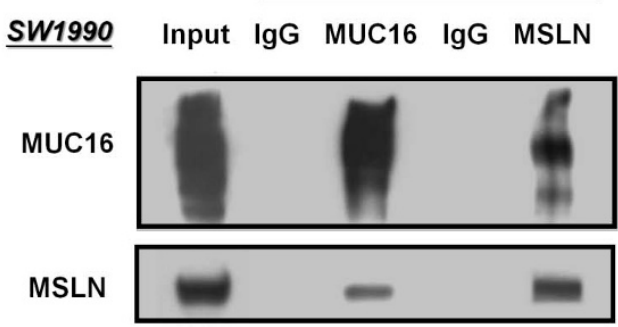

IP

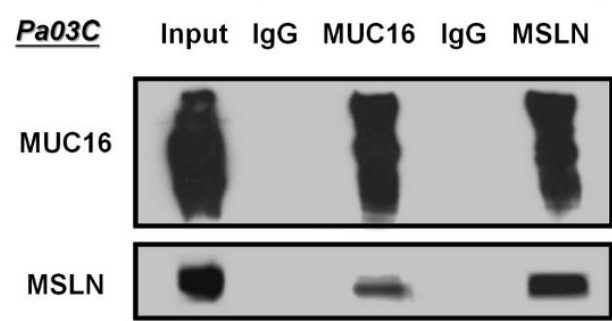

metastatic pancreatic cancer cells is MUC16-dependent, as evidenced by the failure of MUC16-KD SW1990 and Pa03C cells to induce mRNA, protein, and secreted MMP-7 (Fig. 4C-E). As a control, MMP-9 protein levels remained unchanged between scramble control and MUC16-KD cells in the presence or absence of human recombinant MSLN (Fig. 4D).

MSLN-MUC16 binding promotes pancreatic cancer cell migration and invasion via MMP-7 activation. We used the Matrigelcoated transwell invasion assay to determine the roles of MSLN, MUC16 and MMP-7 in the invasive potential of pancreatic cancer cells. Scramble control SW1990 and Pa03C cells treated with MSLN $(1 \mu \mathrm{g} / \mathrm{ml})$ exhibited a markedly increased invasive capacity relative to vehicle control cells (Fig. 5A, B). Moreover, MUC16 silencing abrogated the enhanced MSLN-mediated pancreatic cancer invasion (Fig. 5A, B). To delineate whether induction of MMP-7 by MSLN-MUC16 binding enhanced pancreatic cancer cell invasion, SW1990 and Pa03C cells were incubated with MSLN $(1 \mu \mathrm{g} / \mathrm{ml})$ in the presence of an MMP-7 neutralizing antibody or an isotype control. Use of an anti-MMP-7 mAb abolished the enhanced MSLN-induced pancreatic cancer invasion (Fig. 5A, B). In contrast, incubation of SW1990 or Pa03C cells with an active form of human recombinant MMP-7 promoted their invasive potential (Fig. 5C).

We next evaluated the contribution of MSLN and MUC16 to pancreatic cancer cell motility using a microfluidic-based migration chamber, which consists of 4 -walled microchannels of prescribed dimensions through which cells are induced to migrate in response to a chemoattractant ${ }^{28,29}$ (Supplementary Figure 3 ). Single cell motility through collagen I-coated microchannels was tracked in realtime by phase-contrast microscopy. The cross-sectional area of the microchannels $\left(W \mathrm{xH}=6 \times 10 \mu \mathrm{m}^{2}\right)$ was chosen to be comparable to the $8 \mu \mathrm{m}$ pore size in the transwell assay. Treatment of SW1990 cells with MSLN $(1 \mu \mathrm{g} / \mathrm{ml})$ relative to vehicle control for $6 \mathrm{~h}$ prior to their infusion into the cell seeding inlet (Supplementary Figure 3) led to a marked increase in migration speed (Fig. 6A). However, MSLN failed to alter the migratory potential of MUC16-KD SW1990 cells (Fig. 6A and B). Similar observations were made using Pa03C cells (Fig. 6C and D). Our microchannel data are in agreement with our wound healing migration results, which reveal
B MUC16-KD
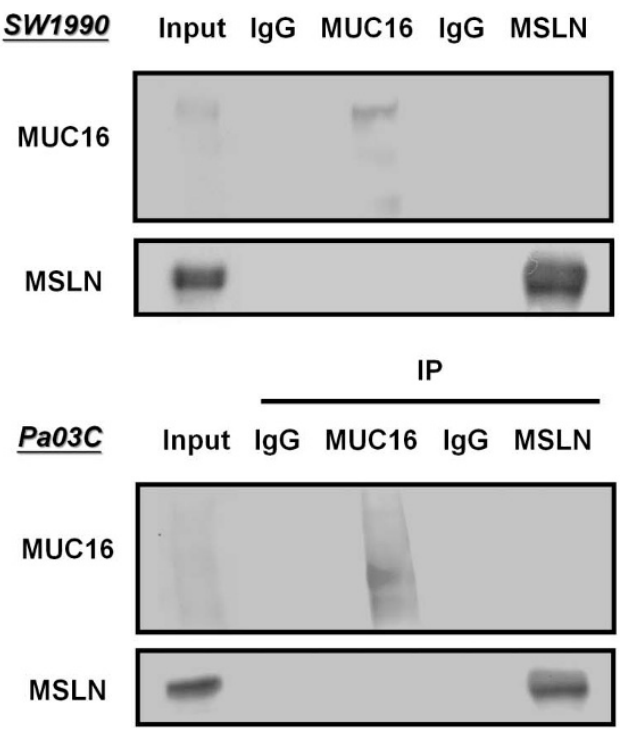

Figure $2 \mid$ MSLN and MUC16 co-immunoprecipitate in pancreatic cancer cells. Whole lysates from scramble control (A) or MUC16-KD (B) SW1990 and Pa03C cells were immunoprecipitated with either an anti-MUC16 or anti-MSLN or an isotype control antibody, and analyzed for MSLN or MUC16 reactivity by immunoblotting. Lysates from SW1990 and Pa03C cells were also analyzed as input controls. 
A

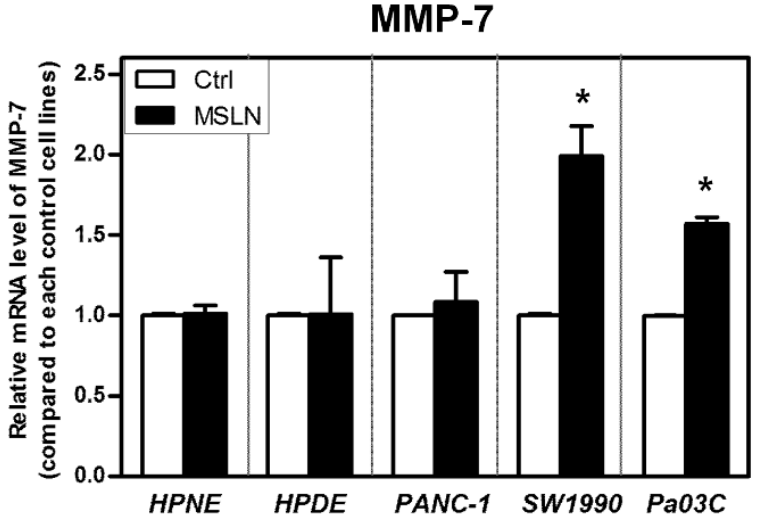

B

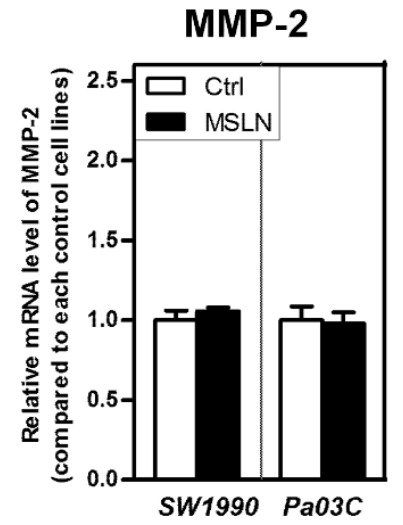

C

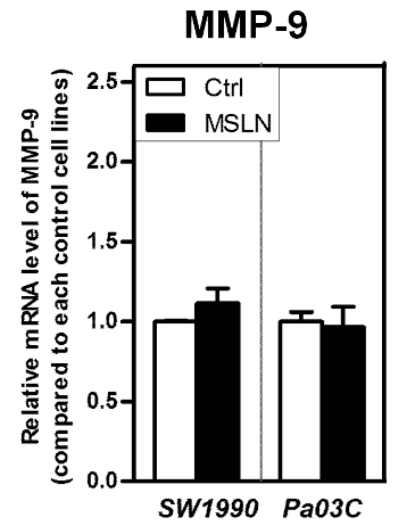

D

\section{Normal pancreas}

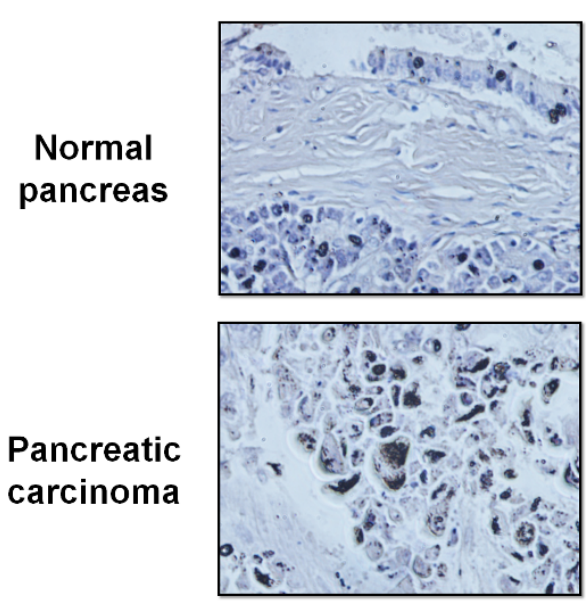

MSLN
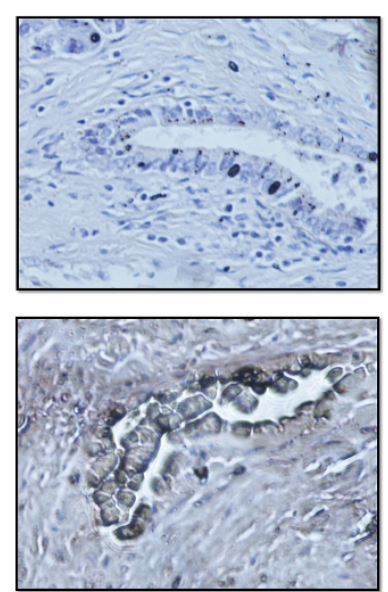

MMP-7
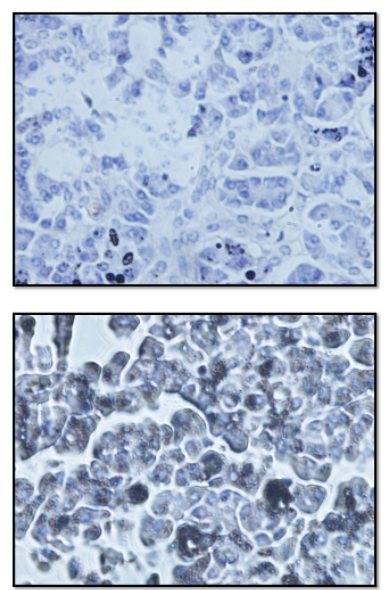

Figure 3 MUC16 expression correlates with MSLN-mediated MMP-7 induction in pancreatic cancer cells. hTERT-HPNE, HPDE, PANC-1, SW1990, and Pa03C cells were starved in serum-free medium and incubated in the presence or absence of MSLN ( $1 \mu \mathrm{g} / \mathrm{ml}$ ) overnight. (A) MMP-7, (B) MMP-2, and (C) MMP-9 mRNA levels were then determined by qRT-PCR. GAPDH served as internal control. Data represent the mean \pm S.E. of at least three independent experiments. ${ }^{*}, p<0.01$ with respect to corresponding control. (D) MUC16, MSLN, and MMP-7 expression in pancreatic cancer tissue specimens was determined by immunohistochemical staining using an anti-MUC16, anti-MSLN, or anti-MMP-7 antibody, respectively. Strong immunostaining was detected in $\sim 90 \%$ of cancerous tissues, whereas no immunoreactivity was present in the ducts or acini of normal pancreas tissue.

that scramble control but not MUC16-KD cells treated with MSLN closed the wounding gap more efficiently (supplementary Fig. 4). In view of our observations showing that MSLN-MUC16 binding induces MMP-7 activation, we sought to determine the role of MMP-7 in cell motility. As shown in Fig. 6E, a MMP-7 neutralizing antibody markedly attenuated the migration speed of MSLNtreated SW1990 and Pa03C cells. Moreover, addition of exogenous MMP-7 enhanced the migration speed of scramble control SW1990 and $\mathrm{Pa} 03 \mathrm{C}$ cells (Fig. 6F).

MSLN-MUC16 interaction activates MMP-7 and induces pancreatic cancer cell motility and invasion via a p38 MAPK-dependent pathway. We next wished to decipher the molecular pathway(s) by which MSLN-MUC16 interaction promotes pancreatic cancer cell motility and invasion. Prior work has reported the activation of extracellular-signal-regulated kinase (ERK), phosphatidylinositol 3kinase (PI3K)/Akt, and p38 to be involved in pancreatic cancer cell migration and invasion ${ }^{30,31}$. MSLN stimulation increased ERK1/2 phosphorylation in both scramble control and MUC16-KD SW1990 cells without impairing total ERK1/2 levels (Fig. 7A), suggesting that
MSLN-mediated ERK1/2 activation is independent of MUC16 expression. In addition, incubation with the ERK specific inhibitor PD98059 suppressed both the phosphorylation of MSLN-mediated ERK and MMP-7 protein expression (supplementary Fig. 5). MSLN treatment failed to alter the total and phosphorylated levels of Akt (data not shown), thereby eliminating the possibility of Akt involvement in this process. Interestingly, MSLN induced p38 phosphorylation in scramble control, but not MUC16-KD, SW1990 cells without affecting total p38 levels (Fig. 7A). This finding suggests that MSLN may regulate p38 MAPK activity via binding to MUC16 on the SW1990 cell surface. Indeed, incubation with the p38 MAPK specific inhibitor SB203580 abolished both the phosphorylation of MSLNmediated p38 MAPK and MMP-7 protein expression (Fig. 7B). Along these lines, SB203580 or an MMP-7 antisense oligonucleotide blocked the MSLN-mediated invasive potential of SW1990 cells down to basal levels (Fig. 7C). Similar trends were noted in our cell motility assays (Fig. 7D). Taken together, our data suggest that MSLN binding to MUC16 on pancreatic cancer cell surface induces MMP-7 activation through a p38 MAPK-dependent pathway, thereby promoting the cell invasive and migratory potentials (Fig. 8). 
A

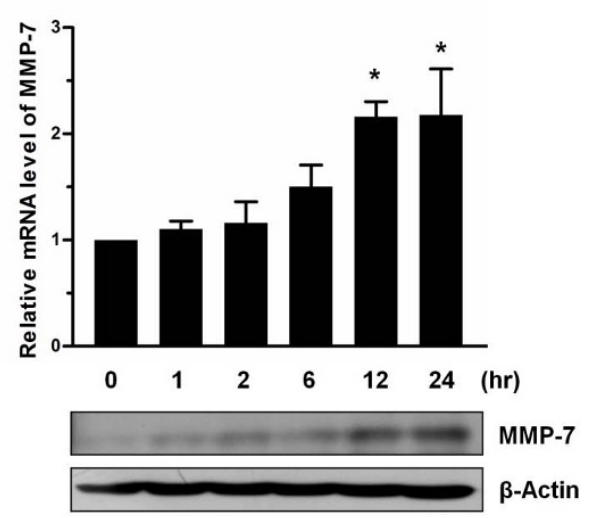

D

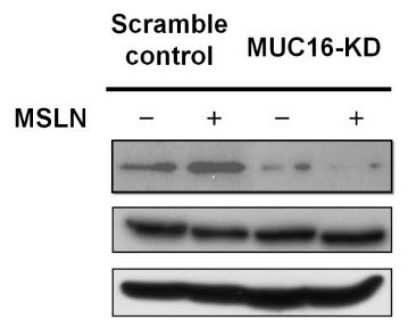

$\beta$-Actin
B

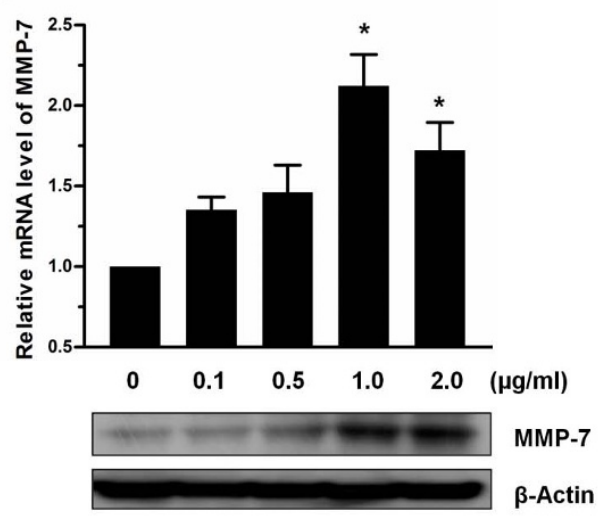

$\beta$-Actin
C

SW1990

Pa03C

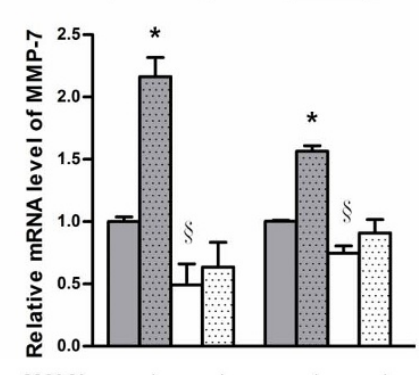

MSLN -+-+-+-+

Control shRNA ++--++-MUC16 ShRNA --++--++

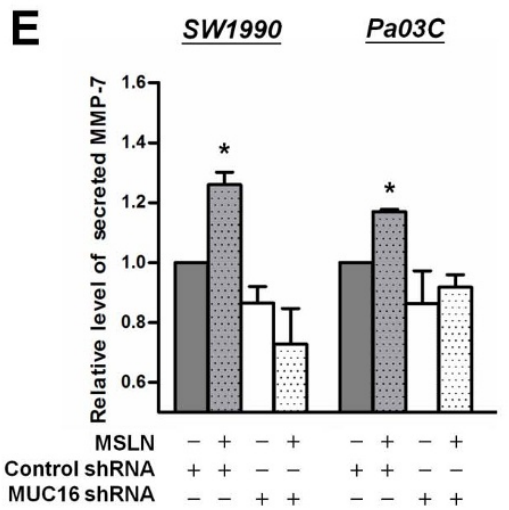

Figure $4 \mid$ MSLN-MUC16 interaction induces MMP-7 synthesis in pancreatic cancer cells. (A) SW1990 cells were starved in serum-free medium overnight and incubated with MSLN $(1 \mu \mathrm{g} / \mathrm{ml})$ for the indicated periods of time. The mRNA levels of MMP-7 were quantified by qRT-PCR. GAPDH served as internal control. Data represent the mean \pm S.E. of at least three independent experiments. ${ }^{*}, p<0.05$ with respect to cells treated with MSLN $(1 \mu \mathrm{g} / \mathrm{ml})$ for $0 \mathrm{~h}$. MMP-7 protein expression from SW1990 cell lysates was analyzed using Western blotting. $\beta$-actin served as an internal control.

(B) SW1990 cells were starved in serum-free medium overnight and incubated with different concentrations of MSLN (0-2.0 $\mu \mathrm{g} / \mathrm{ml})$ for $12 \mathrm{~h}$. MMP-7 mRNA and protein expression were then analyzed by qRT-PCR and Western blotting, respectively. Data from qRT-PCR represent the mean \pm S.E. of three independent experiments. *, $p<0.05$ with respect to untreated control cells. (C, D) Scramble control or MUC16-KD SW1990 and Pa03C cells were serum-starved overnight and then incubated for $12 \mathrm{~h}$ in the presence or absence of MSLN $(1 \mu \mathrm{g} / \mathrm{ml})$. MMP-7 mRNA (C) and protein (D) levels were quantified by qRT-PCR and immunoblotting, respectively. Data represent the mean \pm S.E. of at least three independent experiments. ${ }^{*}, p<0.01$ and $\S, p$ $<0.05$ with respect to the corresponding scramble control cells. (E) Conditioned media from scramble control or MUC16-KD pancreatic cancer cells pretreated with MSLN $(1 \mu \mathrm{g} / \mathrm{ml})$ for $12 \mathrm{~h}$ were collected and analyzed for MMP-7 secretion. Data are reported as the fold of MMP-7 levels detected in the conditioned medium of each cell line compared to that in the medium of untreated scramble control cells. Data represent the mean \pm S.E. of three independent experiments. ${ }^{*}, p<0.05$ with respect to corresponding untreated scramble control cells.

\section{Discussion}

MUC16 expression in pancreatic ductal adenocarcinoma correlates with poor survival independent of other prognosis predictors ${ }^{15}$. CA125, the specific epitope expressed on MUC16, has been suggested as a marker for diagnosis of pancreatic cancer with high positive predictive value at $\sim 88 \%{ }^{32}$. MSLN, physiologically present on mesothelial cells lining the peritoneum ${ }^{1}$, is overexpressed in the majority of pancreatic cancer cells, but is minimally detected in normal pancreas and in chronic pancreatitis ${ }^{2,3}$. Elevated levels of circulating MSLN are detected in the serum of $99 \%$ of patients with pancreatic adenocarcimona but not in healthy individuals as assessed by ELISA assays ${ }^{5}$, thereby suggesting the potential of MSLN as a diagnostic marker and a therapeutic target for pancreatic cancer. The molecular mechanism(s) underlying the overexpression of MSLN in pancreatic cancer tissue is not well understood. However, some studies suggest that this is attributed to hypomethylation of the MSLN promoter region ${ }^{33}$ and its upstream enhancer containing a transcription enhancer factor (TEF-1) dependent MCAT motif ${ }^{34}$.
Interestingly, recent immunohistological studies have shown that MUC16 and MSLN are co-localized at the invading edge in pancreatic cancer tissue specimens, and this co-expression is statistically associated with a poor prognosis and unfavorable patient outcome $^{19,20}$. However, the molecular mechanism by which MSLNMUC16 binding promotes pancreatic cancer progression has yet to be deciphered. We herein demonstrate that the molecular interaction of MSLN with MUC16 expressed by pancreatic cancer cells induces MMP-7 synthesis, and promotes their migratory and invasive potentials. Indeed, MSLN fails to induce MMP-7 in MUC16-knockdown pancreatic cancer cells as well as in nonmalignant cells (i.e. hTERTHPNE and HPDE) and pancreatic cancer cells (i.e. PANC-1), which are devoid of MUC16. The binding interaction between MSLN and MUC16 selectively stimulates MMP-7, but not MMP-2 or -9, expression in pancreatic cancer cells, thereby offering a novel perspective on the poor prognosis and unfavorable patient outcomes associated with MSLN and MUC16 co-overexpression ${ }^{19,20}$, and MMP-7 activation ${ }^{24-26}$ in PC. 
A
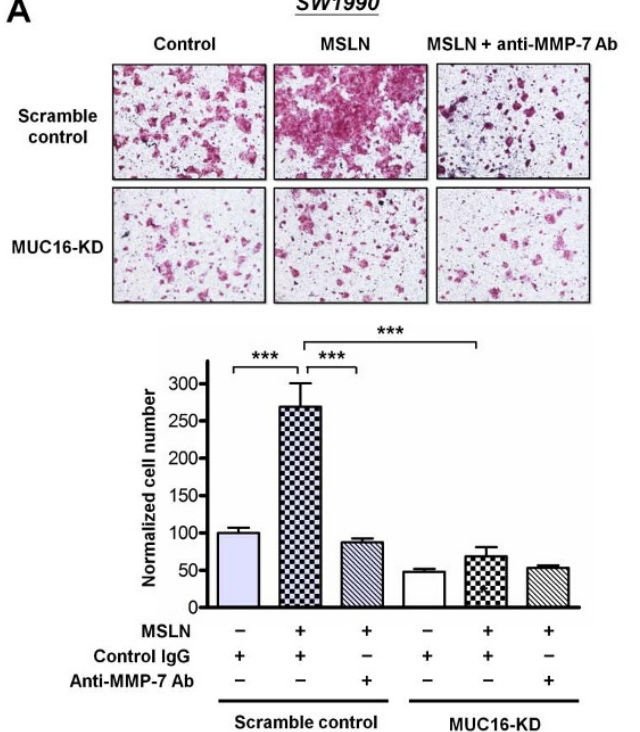

B
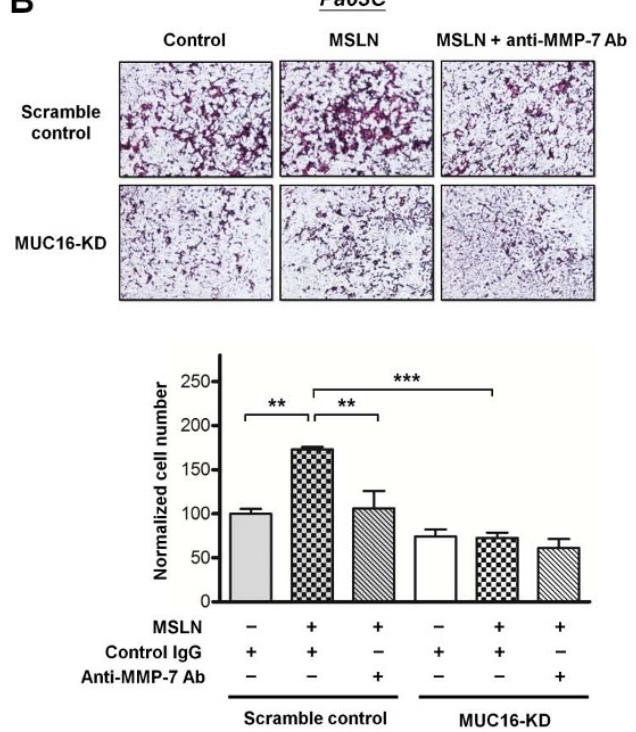

C
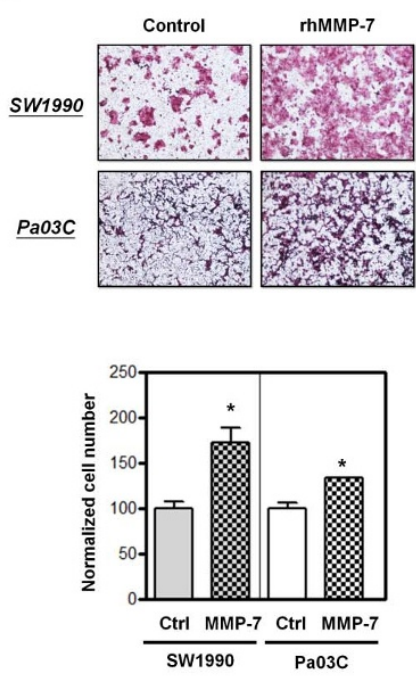

Figure 5 | MSLN-MUC16 interaction promotes pancreatic cancer cell invasion via MMP-7 activation. Scramble control or MUC16-KD SW1990 (A) or $\mathrm{Pa} 03 \mathrm{C}$ (B) cells were incubated with MSLN $(1 \mu \mathrm{g} / \mathrm{ml})$ in the presence of either a neutralizing MMP-7 antibody $(2 \mu \mathrm{g} / \mathrm{ml})$ or an isotype control and then used in transwell invasion assays. Data are reported as normalized cell number that invaded through the transwell membrane relative to untreated scramble control (100\%), and represent the mean \pm S.E. of three independent experiments. $* *, p<0.01$; ***, $p<0.001$ (one-way ANOVA followed by Tukey test). (C) SW1990 and Pa03C pancreatic cancer cells were incubated with either human recombinant active MMP-7 ( $2 \mu \mathrm{g} / \mathrm{ml})$ or vehicle control, and then used in transwell invasion assays. Data are reported as normalized cell number that invaded through the membrane relative to vehicle controltreated cells $(100 \%)$, and represent the mean \pm S.E. of three independent experiments. ${ }^{*}, p<0.05$ with respect to vehicle control cells (Student's t-test).

A

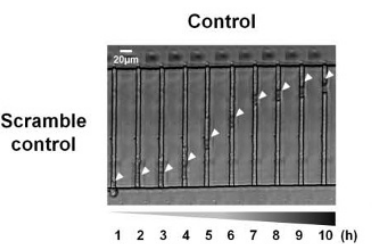

$\begin{array}{llllllllllll}1 & 2 & 3 & 4 & 5 & 6 & 7 & 8 & 9 & 10\end{array}$

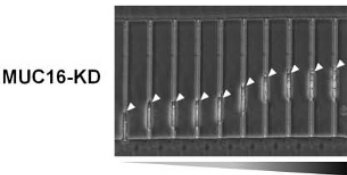

$\begin{array}{lllllllllllllllllllll}1 & 2 & 3 & 4 & 5 & 6 & 7 & 8 & 9 & 10 & \text { (h) } & 1 & 2 & 3 & 4 & 5 & 6 & 7 & 8 & 9 & 10\end{array}$

B
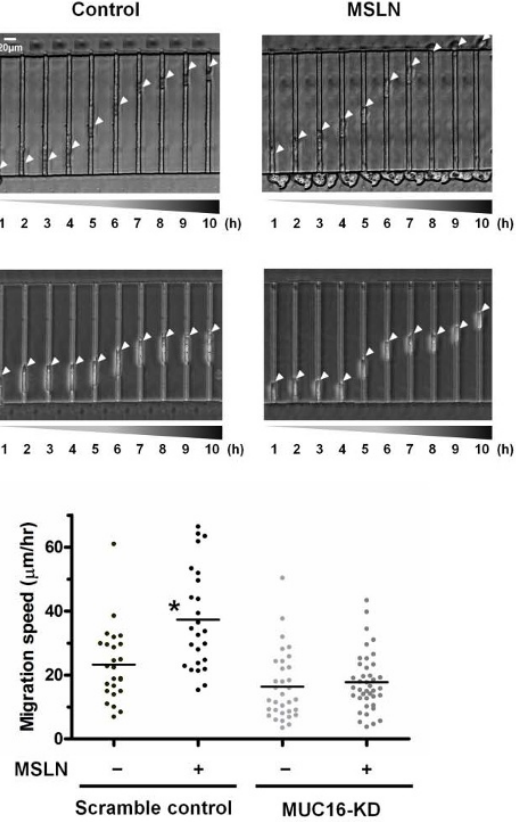

C

D
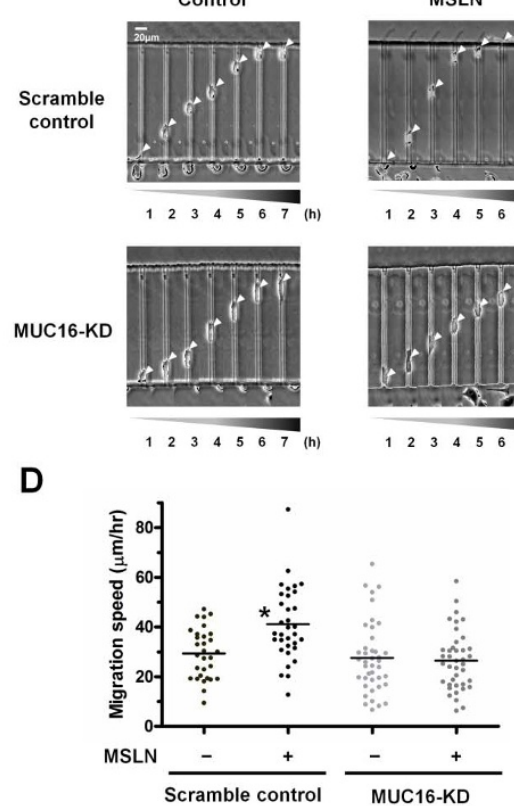

$\mathbf{E}$
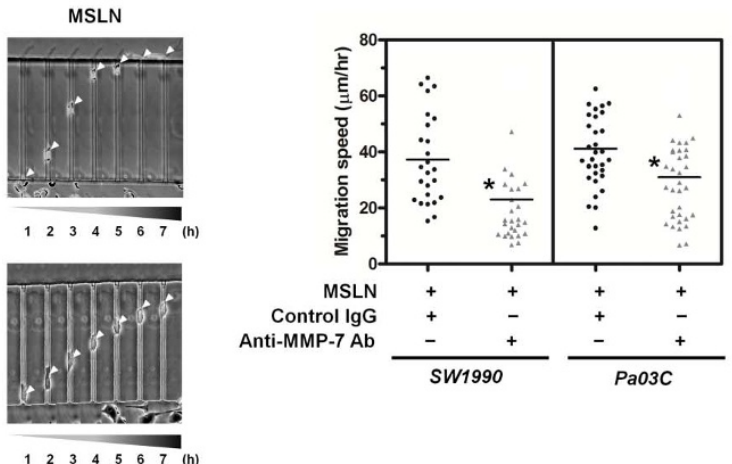

$\mathbf{F}$

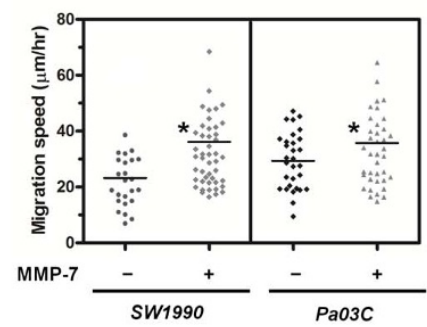

Figure 6 MSLN binding to MUC16 promotes pancreatic cancer cell motility via MMP-7 activation. Representative time-lapse images of scramble control and MUC16-KD SW1990 (A) and Pa03C (C) pancreatic cancer cells migrating through channels of prescribed dimensions $(W \mathrm{x} H \mathrm{x} L=6 \times 10 \times$ $200 \mu \mathrm{m}$ ) using 10\% FBS as chemoattractant. In all experiments, cells were incubated with or without MSLN ( $1 \mu \mathrm{g} / \mathrm{ml})$ for $6 \mathrm{~h}$ before being seeded to the microchannel device. The average migration speed of individual scramble control and MUC16-KD SW1990 (B) and Pa03C (D) cells was determined over a 10 h period for $>30$ cells from three independent experiments. *, $p<0.05$ with respect to scramble control and MSLN-treated MUC16-KD cells. (E) The average migration speed of MSLN-stimulated SW1990 and Pa03C cells in the presence of either an MMP-7 neutralizing antibody (2 $\mu \mathrm{g} / \mathrm{ml})$ or an isotype control was quantified for $>30$ cells from three independent experiments. ${ }^{*}, p<0.05$ with respect to the control treatment. (F) The average migration speed of SW1990 and Pa03C cells in the presence or absence of human recombinant active MMP-7 ( $2 \mu \mathrm{g} / \mathrm{ml})$ was quantified for $>30$ cells from three independent experiments. *, $p<0.05$ with respect to untreated control. 
A

\section{Scramble control MUC16-KD}

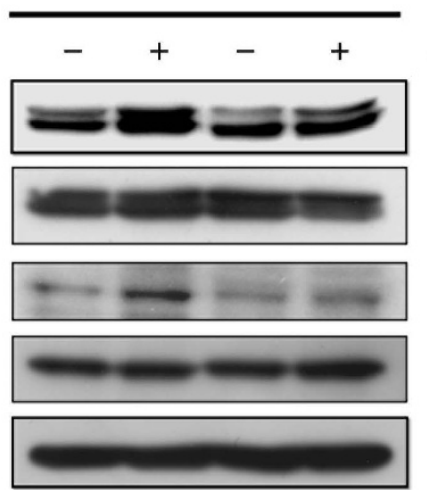

MSLN

p-ERK

ERK

p-p38

p38

$\beta$-actin
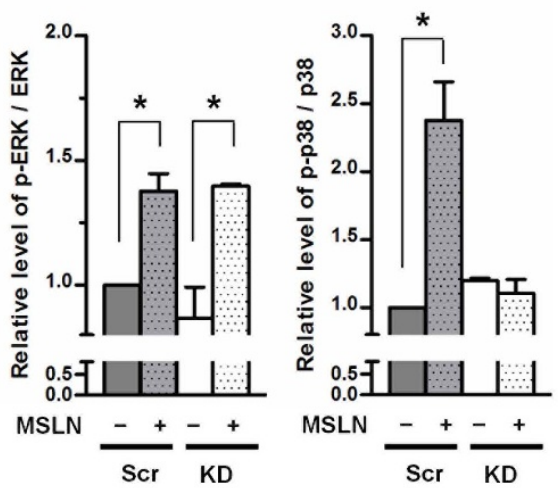

C

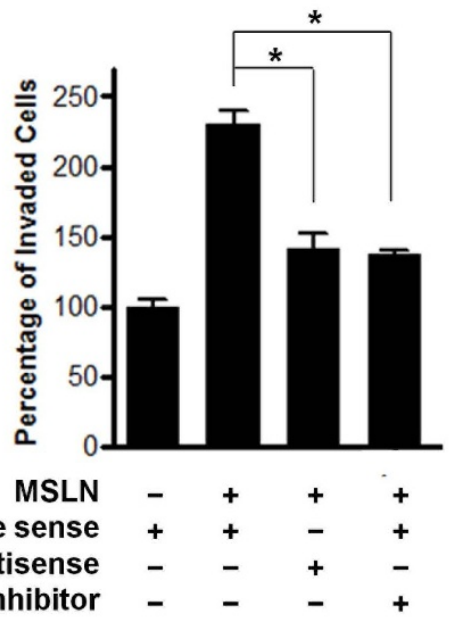

B

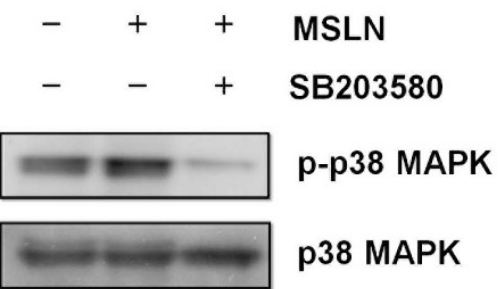

MMP-7

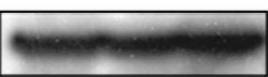

$\beta$-actin

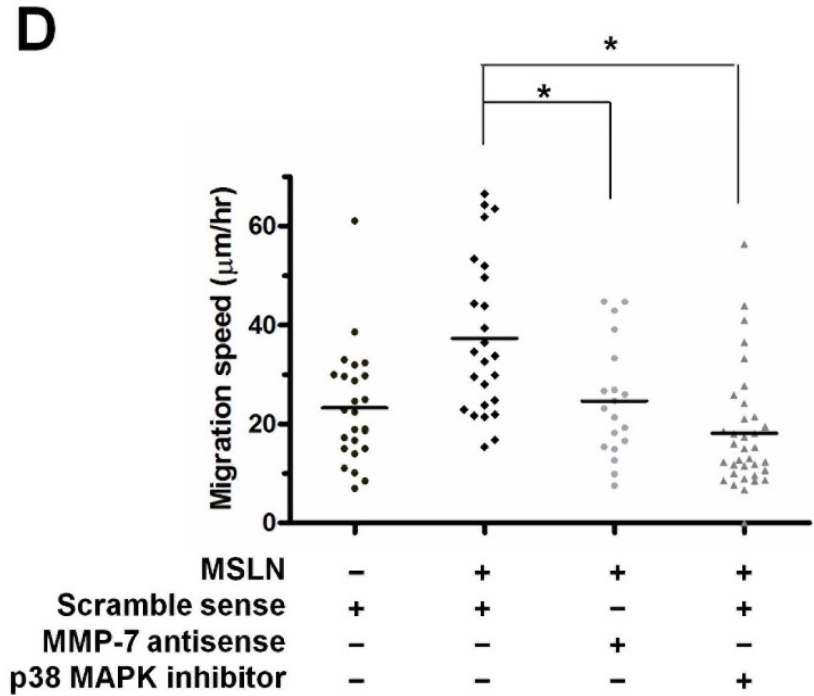

Figure 7 MSLN-MUC16 interaction promotes pancreatic cancer cell motility and invasion via MMP-7 induced by a p38 MAPK-dependent pathway. (A) Scramble control and MUC16-KD SW1990 cells were serum-starved overnight, and then treated with MSLN (1 $\mu \mathrm{g} / \mathrm{ml}) \mathrm{for} 12 \mathrm{~h}$. The levels of phospho-ERK1/2 (Thr202/Tyr204) and phospho-p38 MAPK (Thr180/Tyr182) from whole cell lysates were analyzed by immunoblotting using specific Abs. Equal loading in each lane was ensured by the similar intensities of total ERK1/2, p38 MAPK, and $\beta$-actin. (B) SW1990 cells were incubated with $\operatorname{MSLN}(1 \mu \mathrm{g} / \mathrm{ml})$ for $12 \mathrm{~h}$ in the presence or absence of the p38 MAPK inhibitor SB203580 $(20 \mu \mathrm{M})$. The levels of phospho-p38 MAPK (Thr180/Tyr182) and MMP-7 expression from cell lysates were analyzed by Western blotting using specific Abs. Equal loading in each lane is ensured by the similar intensities of total p38 MAPK and $\beta$-actin. These Western blots are representative of three independent experiments, all revealing similar results. The intensity of bands was quantified using the NIH ImageJ software and then normalized with respect to the value obtained for the untreated control. (C, D) SW 1990 cells were stimulated with MSLN $(1 \mu \mathrm{g} / \mathrm{ml})$ in the presence or absence of SB203580 $(20 \mu \mathrm{M})$ or an MMP-7 antisense oligonucleotide $(50 \mathrm{nM})$, and then subjected to either transwell invasion or microchannel motility assays. (C) Data are reported as percentage of untreated control cells that invaded through the transwell membrane, and represent the mean \pm S.E. of three independent experiments. (D) The average migration speed of individual cells was determined over a $10 \mathrm{~h}$ period for $>30$ cells from three independent experiments for each of the indicated conditions. $*, p<0.01$. 


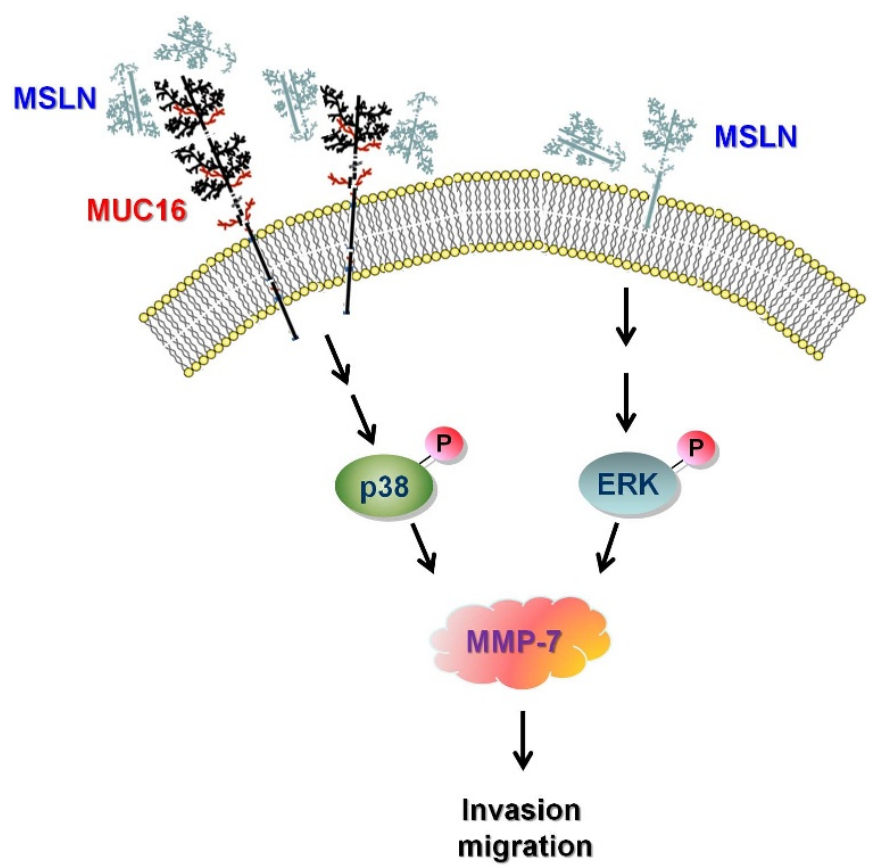

Figure 8 Proposed molecular pathway induced by MSLN-MUC16 binding, which results in MMP-7 induction in pancreatic cancer cells. The binding of MSLN to MUC16 present on the pancreatic cancer cell surface activates a p38 MAPK-dependent pathway, which in turn upregulates MMP-7 synthesis, resulting in increased invasive and migratory potentials. In the absence of MUC16 expression by pancreatic cancer cells, MSLN is capable of upregulating MMP-7 expression via activation of an ERK-dependent pathway.

The role of MMPs in cancer cell invasion and metastasis has been well documented in a variety of tumor types, including pancreatic cancer $^{35}$. MMPs mediate ECM digestion, thereby facilitating cancer cell invasion and metastasis. Importantly, MSLN expression correlates with MMP-7 production and increased cell invasive capability in ovarian cancer ${ }^{7}$. Malignant pleural mesothelioma cells overexpressing MSLN were found preferentially at the tumor invasion front and co-localized with sites of MMP-9 expression ${ }^{8}$. Additionally, MSLN silencing resulted in the reduction of mesothelioma, ovarian, and pancreatic tumor cell invasiveness ${ }^{9}$. Along these lines, we herein show that MSLN-treated MUC16-expressing pancreatic cancer cells display $>2$-fold increased MMP-7 expression and $\sim 3$-fold higher invasive potential relative to either untreated MUC16-expressing pancreatic cancer cells or MSLN-treated MUC16-negative cells. These observations clearly show that the MSLN-MUC16 molecular interaction is responsible for MMP-7 induction and the increased invasive potential. Of note, MMP-7 is primarily present at the invasive front of the pancreatic tumors ${ }^{21}$, and has been suggested as an independent prognostic factor due to its strong correlation with lymph node metastasis and poor survival of patients ${ }^{24-26}$. In our study, MMP-7 expression tended to be lower in MUC16-KD cells relative to scramble controls even in the absence of exogenously added MSLN, suggesting that endogenous MSLN may contribute to MMP-7 synthesis via its interaction with MUC16 on pancreatic cancer cell surface.

Prior work has suggested a role for MSLN in cancer cell migration $^{6,9}$. However, these observations were made using either the traditional Boyden chamber or wound healing assays, which fail to replicate the physiological environment encountered in vivo. Cells migrate in vivo through three-dimensional (3D) ECMs and 3D longitudinal tracks with bordering $2 \mathrm{D}$ interfaces (i.e. channels) ${ }^{36}$. We herein used a microchannel assay ${ }^{28,29}$ to track chemotactic-driven migration of single pancreatic cancer cells in real-time through confined (narrow) channels encountered in vivo ${ }^{36}$. Our data reveal that incubation of MUC16-expressing pancreatic cancer cells with exogenously added MSLN markedly increased their motility through narrow channels, and was suppressed by the use of an MMP-7 neutralizing antibody. This finding is in line with previous observations showing that MMP-7 plays a crucial role in the regulation of colon and gastric cancer cell migration ${ }^{37,38}$. Of note, activation of MMP-7 may also be involved in the induction of pancreatic carcinoma cell dissociation and disruption of tight junctions from the primary tumor tissue . $^{39}$.

MSLN has been reported to be involved in cancer cell survival and proliferation $^{6,9}$. However, our data show that the rate of cell proliferation in either scramble control or MUC16-KD pancreatic cancer cells is not significantly altered by MSLN stimulation for up to $24 \mathrm{~h}$ (supplementary Fig. 6). This finding along with our single cell motility assays rule out the potential involvement of cell doubling in the enhanced MSLN-stimulated invasive and migratory potentials of pancreatic cancer cells. However, we cannot exclude a potential MSLN effect on cell proliferation at longer time points.

The involvement of ERK, PI3K/Akt, and p38 MAPK as mediators of cell invasion and migration has been documented in numerous types of malignancies, including pancreatic cancer ${ }^{30,31}$. Here, we observed that MSLN stimulation of both MUC16-expressing and MUC16-KD pancreatic cancer cells markedly enhanced the phosphorylation of ERK but not PI3K/Akt. This finding is in line with previous reports showing that MSLN regulates ERK activation in ovarian cancer cells ${ }^{7}$ and mesothelioma cells ${ }^{9}$. However, MUC16 is not likely involved in the MSLN-induced ERK activation given that ERK is activated in both MUC16-expressing and MUC16-KD cells. Interestingly, we herein report that MSLN induces activation of p38 MAPK in a MUC16-dependent manner in pancreatic cancer cells, as evidenced by the increased levels of p38 MAPK phosphorylation in MSLN-stimulated scramble control but not MUC16-KD cells. Moreover, treatment with the p38 MAPK inhibitor SB203580 abrogates the p38 MAPK phosphorylation induced by the MSLNMUC16 molecular interaction without altering total p38 MAPK levels. This pharmacological intervention also markedly suppressed MMP-7 synthesis and pancreatic cancer cell motility and invasion. The role of p38 MAPK-activated MMP-7 in the enhancement of invasiveness and motility of pancreatic cancer cells stimulated with MSLN was validated by the use of an MMP-7 neutralizing antibody and an MMP-7 antisense oligonucleotide. Taken together, our data illustrate the synergistic roles of MUC16 and MSLN in the regulation of MMP-7 via a p38 MAPK-dependent pathway, which results in the promotion of cell motility and invasion in pancreatic carcinoma cells. Our data contribute to a better understanding of the role of MSLN-MUC16 binding interaction in pancreatic cancer cell invasion and metastasis.

\section{Methods}

Cell culture. Human pancreatic nonmalignant epithelial hTERT-HPNE cells and carcinoma cell lines PANC-1 and SW1990 were obtained from the ATCC (Manassas, VA). The human pancreatic ductal epithelial (HPDE) cells and adenocarcinoma cell line Pa03C have been previously described ${ }^{40}$. hTERT-HPNE cells were cultured in medium containing three volumes of glucose-free DMEM, one volume of Medium M3 base (InCell, San Antonio, TX), 5\% FBS, $5.5 \mathrm{mM}$ glucose, $10 \mathrm{ng} / \mathrm{mL}$ human recombinant EGF, and $50 \mu \mathrm{g} / \mathrm{ml}$ gentamicin. PANC-1, SW 1990, and Pa03C were cultured in DMEM with $10 \%$ FBS. HPDE cells were cultured in keratinocyte-SFM supplemented with $0.1 \mathrm{ng} / \mathrm{ml}$ epidermal growth factor and $30 \mu \mathrm{g} / \mathrm{ml}$ bovine pituitary extract (Invitrogen, Carlsbad, CA). MUC16-knockdown SW1990 and Pa03C cell lines were generated as previously described ${ }^{27,41,42}$. Prior to use, cells were harvested by mild trypsinization, and surface glycoproteins were regenerated, as previously described $^{41,43,44}$

Mesothelin-mediated cell binding assay. 96-well plates were coated with human recombinant MSLN (R\&D systems, Minneapolis, MN) or PBS as vehicle control overnight before incubation with D-PBS/1\% BSA for $1 \mathrm{~h} .100 \mu \mathrm{l}$ of cell suspension $\left(10^{4}\right.$ cells/well $)$ were seeded in triplicate onto the plates. After $30 \mathrm{~min}$ of incubation at 
$37^{\circ} \mathrm{C}$, the suspension was aspirated off, and the wells were gently washed with D-PBS. The number of cells adherent to the plate was then determined by WST- 1 assay (Roche Molecular Biochemicals, Indianapolis, IN) according to the manufacturer's instructions.

Flow cytometry. Surface expression of MUC16 on cells was assessed by single-color immunofluorescence and flow cytometry as previously described ${ }^{27}$.

Quantitative reverse transcriptase-polymerase chain reaction (qRT-PCR). qRTPCR assays were performed as previously described ${ }^{45,46}$. The forward (F) and reverse (R) primers were as follows: MMP-2, F-TCTCCTGACATTGACCTTGGC and RCAAGGTGCTGGCTGAGTAGATC; MMP-7, F-TCCAACCTATGGAAATGG AGA and R-GGAGTGGAGGAACAGTGCTT; MMP-9, F-ACGTGACCTAT GACATCCTGCAGT and R-TTGTATCCGGCAAACTGGCTCCTT; GAPDH, F-CCACCCATGGCAAATTCCATGGCA, R-TCTAGACGGCAGGTCAGGT CCACC.

Immunohistochemistry. Pancreatic tissue microarrays (US Biomax, Rockville, MD) included 60 carcinoma tissue cores and 12 normal tissue cores, which were $1.5 \mathrm{~mm}$ in diameter and $5 \mu \mathrm{m}$ in thickness. Slides were first deparaffinized with xylene, rehydrated in a graded series of ethanol, and submerged in 3\% hydrogen peroxide to eliminate endogenous peroxidase activity. Immunohistochemical staining with antibodies for MUC16 (clone M11; Dako, Burlington, ON, Canada), MSLN (clone MN-1; Novus Biologicals, Littleton, CO), and MMP-7 (clone JL07; Santa Cruz) were performed according to standard procedures described previously ${ }^{41}$. Samples stained with matched $\operatorname{IgG}$ or unstained with the primary $\mathrm{mAb}$ were used as negative controls.

Cell lysis and immunoprecipitation. Whole cell lysates for Western blotting or immunoprecipitation assays were prepared as previously described ${ }^{42,47,48}$. MUC16 and MSLN were immunoprecipitated from cell lysates using anti-MUC16 (clone $\mathrm{X} 306$ or M11) and anti-MSLN (clone MN-1) mAbs, respectively, and recombinant protein $\mathrm{G}$ agarose spheres (Invitrogen) ${ }^{42,47,49}$.

Western blotting. Western blotting assays were performed as previously described $^{27,50}$ and stained with antibodies for MUC16, MSLN, MMP-7, MMP-9, $\beta$-actin, or signaling proteins including ERK1/2, p-ERK1/2 (Thr202/Tyr204), Akt, p-Akt (Ser473), p38 MAPK, and p-p38 MAPK (Thr180/Tyr182) (Cell Signaling Technology, Danvers, MA).

Enzyme-linked immunosorbent assay (ELISA). MUC16-KD and scramble control cells were seeded in 6-well plates $\left(5 \times 10^{5} /\right.$ well $)$ and starved in serum-free medium overnight, followed by treatment with MSLN at $1.0 \mu \mathrm{g} / \mathrm{ml}$ for $12 \mathrm{~h}$. Supernatants were collected, and total amount of secreted MMP-7 from cells was quantified using Human total MMP-7 DuoSet ELISA development systems (R\&D Systems) according to the manufacturer's instructions. Data were then normalized to the total cell lysate protein concentration of the sample as measured via BCA assays and corrected for background against serum-free medium that had not been incubated with cells.

Transwell invasion assay. MUC16-KD and scramble control cells treated with MSLN $(1 \mu \mathrm{g} / \mathrm{ml})$ or vehicle control were seeded on 24 -well transwell inserts $(8 \mu \mathrm{m}$ pore size) pre-coated with Matrigel (Becton Dickinson, Bedford, MA) in serum-free media and incubated with either a neutralizing anti-MMP-7 ( $2 \mu \mathrm{g} / \mathrm{ml})(\mathrm{R} \& \mathrm{D}$ systems) or a control IgG antibody, whereas the bottom chamber contained media with $10 \% \mathrm{FBS}$ as chemoattractant. After $24 \mathrm{~h}$ incubation, cells on the upper side of the inserts were removed with cotton-tipped swabs, and cells that had penetrated through Matrigel were fixed with 3.7\% formaldehyde and stained with D-PBS/0.1\% crystal violet. Invaded cells were counted at $\times 100$ magnification in 5 random fields of view by phase-contrast microscopy. In select experiments, cells were treated with human active MMP-7 (2 $\mu \mathrm{g} / \mathrm{ml})$ (EMD Chemicals, Gibbstown, NJ) and used in invasion assays.

Microchannel migration assay. The fabrication and use of the microchannel device for cell migration was recently described ${ }^{28,29}$. Briefly, the microchannels of prescribed dimensions $(W x H x L=6 \times 10 \times 200 \mu \mathrm{m})$ were pre-coated with $20 \mu \mathrm{g} / \mathrm{ml}$ of collagen I for $1 \mathrm{~h}$ and washed with PBS for $1 \mathrm{~min}$. MUC16-KD or scramble control cells $(1 \times$ $\left.10^{5}\right)$ in the presence or absence of MSLN $(1 \mu \mathrm{g} / \mathrm{ml})$ were seeded at the cell inlet wall (Fig S3). Cell migration was induced using $10 \% \mathrm{FBS}$ as chemotactic stimulus. Migration along the chemoattractant gradient was recorded at multiple-stage positions via controlled stage automation (Nikon, Japan) in conjunction with phasecontrast microscopy. To calculate the cell migration velocity, the cell center was identified as the midpoint between poles of the cell body and was tracked for changes in $\mathrm{Y}$ position at $20 \mathrm{~min}$ intervals over a 10 hour period to generate an average value.

Cell viability assay. Scramble control and MUC16-KD cells were seeded in triplicate wells $\left(10^{4}\right.$ cells/well) onto 96 -well plates and starved in serum-free media overnight followed by treatment with MSLN $(1 \mu \mathrm{g} / \mathrm{ml})$ or vehicle control for $0,6,12$, and $24 \mathrm{~h}$. Cell viability was then determined by WST-1 assay according to the manufacturer's instructions.

Statistical analysis. Data are expressed as mean \pm S.E. for at least 3 independent experiments. Statistical significance of differences between means was determined by paired Student's t-test or one-way ANOVA, wherever appropriate. If means were shown to be significantly different, multiple comparisons by pairs were performed by the Tukey test. The statistical significance was set at probability values of $p<0.05$.

1. Chang, K. \& Pastan, I. Molecular cloning of mesothelin, a differentiation antigen present on mesothelium, mesotheliomas, and ovarian cancers. Proc Natl Acad Sci U S A 93, 136-40 (1996).

2. Argani, P. et al. Mesothelin is overexpressed in the vast majority of ductal adenocarcinomas of the pancreas: identification of a new pancreatic cancer marker by serial analysis of gene expression (SAGE). Clin Cancer Res 7, 3862-8 (2001).

3. Hassan, R. et al. Mesothelin is overexpressed in pancreaticobiliary adenocarcinomas but not in normal pancreas and chronic pancreatitis. Am J Clin Pathol 124, 838-45 (2005).

4. Huang, C. Y. et al. Serum mesothelin in epithelial ovarian carcinoma: a new screening marker and prognostic factor. Anticancer Res 26, 4721-8 (2006).

5. Johnston, F. M. et al. Circulating mesothelin protein and cellular antimesothelin immunity in patients with pancreatic cancer. Clin Cancer Res 15, 6511-8 (2009).

6. Li, M. et al. Mesothelin is a malignant factor and therapeutic vaccine target for pancreatic cancer. Mol Cancer Ther 7, 286-96 (2008).

7. Chang, M. C. et al. Mesothelin enhances invasion of ovarian cancer by inducing MMP-7 through MAPK/ERK and JNK pathways. Biochem J442, 293-302 (2012).

8. Servais, E. L. et al. Mesothelin overexpression promotes mesothelioma cell invasion and MMP-9 secretion in an orthotopic mouse model and in epithelioid pleural mesothelioma patients. Clin Cancer Res 18, 2478-89 (2012).

9. Wang, K. et al. Inhibition of mesothelin as a novel strategy for targeting cancer cells. PLoS One 7, e33214 (2012).

10. Rump, A. et al. Binding of ovarian cancer antigen CA125/MUC16 to mesothelin mediates cell adhesion. J Biol Chem 279, 9190-8 (2004).

11. Gubbels, J. A. et al. Mesothelin-MUC16 binding is a high affinity, N-glycan dependent interaction that facilitates peritoneal metastasis of ovarian tumors. Mol Cancer 5, 50 (2006)

12. Kaneko, O. et al. A binding domain on mesothelin for CA125/MUC16. J Biol Chem 284, 3739-49 (2009).

13. O'Brien, T. J. et al. The CA 125 gene: an extracellular superstructure dominated by repeat sequences. Tumour Biol 22, 348-66 (2001).

14. Kui Wong, N. et al. Characterization of the oligosaccharides associated with the human ovarian tumor marker CA125. J Biol Chem 278, 28619-34 (2003).

15. Streppel, M. M. et al. Mucin 16 (cancer antigen 125) expression in human tissues and cell lines and correlation with clinical outcome in adenocarcinomas of the pancreas, esophagus, stomach, and colon. Hum Pathol 43, 1755-63 (2012).

16. Haridas, D. et al. Pathobiological implications of MUC16 expression in pancreatic cancer. PLoS One 6, e26839 (2011).

17. Markman, M., Federico, M., Liu, P. Y., Hannigan, E. \& Alberts, D. Significance of early changes in the serum CA-125 antigen level on overall survival in advanced ovarian cancer. Gynecol Oncol 103, 195-8 (2006).

18. Bast, R. C., Jr. et al. CA 125: the past and the future. Int J Biol Markers 13, 179-87 (1998).

19. Shimizu, A. et al. Coexpression of MUC16 and mesothelin is related to the invasion process in pancreatic ductal adenocarcinoma. Cancer Sci 103, 739-46 (2012).

20. Einama, T. et al. Co-expression of mesothelin and CA125 correlates with unfavorable patient outcome in pancreatic ductal adenocarcinoma. Pancreas $\mathbf{4 0}$, 1276-82 (2011)

21. Yamamoto, H. et al. Expression of matrix metalloproteinases and tissue inhibitors of metalloproteinases in human pancreatic adenocarcinomas: clinicopathologic and prognostic significance of matrilysin expression. J Clin Oncol 19, 1118-27 (2001).

22. Bloomston, M., Zervos, E. E. \& Rosemurgy, A. S., 2nd. Matrix metalloproteinases and their role in pancreatic cancer: a review of preclinical studies and clinical trials. Ann Surg Oncol 9, 668-74 (2002).

23. Gress, T. M. et al. Expression and in-situ localization of genes coding for extracellular matrix proteins and extracellular matrix degrading proteases in pancreatic cancer. Int J Cancer 62, 407-13 (1995).

24. Crawford, H. C., Scoggins, C. R., Washington, M. K., Matrisian, L. M. \& Leach, S. D. Matrix metalloproteinase-7 is expressed by pancreatic cancer precursors and regulates acinar-to-ductal metaplasia in exocrine pancreas. J Clin Invest 109, $1437-44$ (2002).

25. Fukushima, H. et al. Association of matrilysin mRNA expression with K-ras mutations and progression in pancreatic ductal adenocarcinomas. Carcinogenesis 22, 1049-52 (2001)

26. Jones, L. E., Humphreys, M. J., Campbell, F., Neoptolemos, J. P. \& Boyd, M. T. Comprehensive analysis of matrix metalloproteinase and tissue inhibitor expression in pancreatic cancer: increased expression of matrix metalloproteinase-7 predicts poor survival. Clin Cancer Res 10, 2832-45 (2004)

27. Chen, S. H., Dallas, M. R., Balzer, E. M. \& Konstantopoulos, K. Mucin 16 is a functional selectin ligand on pancreatic cancer cells. FASEB J 26, 1349-59 (2012).

28. Balzer, E. M. et al. Physical confinement alters tumor cell adhesion and migration phenotypes. FASEB J 26, 4045-56 (2012).

29. Tong, Z. et al. Chemotaxis of cell populations through confined spaces at singlecell resolution. PLoS One 7, e29211 (2012). 
30. Veit, C. et al. Activation of phosphatidylinositol 3-kinase and extracellular signalregulated kinase is required for glial cell line-derived neurotrophic factor-induced migration and invasion of pancreatic carcinoma cells. Cancer Res 64, 5291-300 (2004).

31. Singh, A. K. et al. p38beta MAP kinase as a therapeutic target for pancreatic cancer. Chem Biol Drug Des 80, 266-73 (2012).

32. Cwik, G., Wallner, G., Skoczylas, T., Ciechanski, A. \& Zinkiewicz, K. Cancer antigens 19-9 and 125 in the differential diagnosis of pancreatic mass lesions. Arch Surg 141, 968-73; discussion 974 (2006).

33. Sato, N. et al. Frequent hypomethylation of multiple genes overexpressed in pancreatic ductal adenocarcinoma. Cancer Res 63, 4158-66 (2003).

34. Hucl, T. et al. High cancer-specific expression of mesothelin (MSLN) is attributable to an upstream enhancer containing a transcription enhancer factor dependent MCAT motif. Cancer Res 67, 9055-65 (2007).

35. Sternlicht, M. D. \& Werb, Z. How matrix metalloproteinases regulate cell behavior. Annu Rev Cell Dev Biol 17, 463-516 (2001).

36. Friedl, P. \& Alexander, S. Cancer invasion and the microenvironment: plasticity and reciprocity. Cell 147, 992-1009 (2011)

37. Remy, L., Trespeuch, C., Bachy, S., Scoazec, J. Y. \& Rousselle, P. Matrilysin 1 influences colon carcinoma cell migration by cleavage of the laminin- 5 beta3 chain. Cancer Res 66, 11228-37 (2006).

38. Wroblewski, L. E. et al. Stimulation of MMP-7 (matrilysin) by Helicobacter pylori in human gastric epithelial cells: role in epithelial cell migration. J Cell Sci 116 3017-26 (2003).

39. Tan, X. et al. Involvement of matrix metalloproteinase-7 in invasion-metastasis through induction of cell dissociation in pancreatic cancer. Int J Oncol 26, 1283-9 (2005)

40. Jones, S. et al. Core signaling pathways in human pancreatic cancers revealed by global genomic analyses. Science 321, 1801-6 (2008).

41. Dallas, M. R. et al. Sialofucosylated podocalyxin is a functional E- and L-selectin ligand expressed by metastatic pancreatic cancer cells. Am J Physiol Cell Physiol 303, C616-24 (2012)

42. Thomas, S. N., Zhu, F., Schnaar, R. L., Alves, C. S. \& Konstantopoulos, K. Carcinoembryonic antigen and CD44 variant isoforms cooperate to mediate colon carcinoma cell adhesion to E- and L-selectin in shear flow. J Biol Chem $\mathbf{2 8 3}$ 15647-55 (2008).

43. Burdick, M. M. \& Konstantopoulos, K. Platelet-induced enhancement of LS174T colon carcinoma and THP-1 monocytoid cell adhesion to vascular endothelium under flow. Am J Physiol Cell Physiol 287, C539-47 (2004).

44. McCarty, O. J., Jadhav, S., Burdick, M. M., Bell, W. R. \& Konstantopoulos, K. Fluid shear regulates the kinetics and molecular mechanisms of activation-dependent platelet binding to colon carcinoma cells. Biophys J 83, 836-48 (2002).

45. Wang, P., Zhu, F., Tong, Z. \& Konstantopoulos, K. Response of chondrocytes to shear stress: antagonistic effects of the binding partners Toll-like receptor 4 and caveolin-1. Faseb J 25, 3401-15 (2011).
46. Zhu, F., Wang, P., Kontrogianni-Konstantopoulos, A. \& Konstantopoulos, K. Prostaglandin (PG)D(2) and 15-deoxy-Delta(12,14)-PGJ(2), but not PGE(2), mediate shear-induced chondrocyte apoptosis via protein kinase A-dependent regulation of polo-like kinases. Cell Death Differ 17, 1325-34 (2010).

47. Thomas, S. N., Schnaar, R. L. \& Konstantopoulos, K. Podocalyxin-like protein is an E-/L-selectin ligand on colon carcinoma cells: comparative biochemical properties of selectin ligands in host and tumor cells. Am J Physiol Cell Physiol 296, C505-13 (2009).

48. Hanley, W. D. et al. Variant isoforms of CD44 are P- and L-selectin ligands on colon carcinoma cells. FASEB J 20, 337-9 (2006).

49. Napier, S. L., Healy, Z. R., Schnaar, R. L. \& Konstantopoulos, K. Selectin ligand expression regulates the initial vascular interactions of colon carcinoma cells: the roles of CD44v and alternative sialofucosylated selectin ligands. J Biol Chem 282, 3433-41 (2007).

50. Wang, P., Zhu, F. \& Konstantopoulos, K. Interleukin-6 synthesis in human chondrocytes is regulated via the antagonistic actions of prostaglandin (PG)E2 and 15-deoxy-Delta(12,14)-PGJ2. PLoS One 6, e27630 (2011).

\section{Acknowledgements}

This work was supported by grants from the National Cancer Institute (awards U54-CA143868 and RO1-CA101135), National Science Foundation (NSF-1159823), and Kleberg Foundation.

\section{Author contributions}

S.H.C. conceived the experiments, performed all of the experiments, analyzed and interpreted data, and wrote the manuscript. W.C.H. contributed to the experimental design, performed the experiments in Fig. 6, and edited the manuscript. P.W. contributed to the experimental design and edited the manuscript. C.P. prepared the experimental device used in Fig. 6 and edited the manuscript. K.K. conceived the experiments, interpreted data, and wrote the manuscript.

\section{Additional information}

Supplementary information accompanies this paper at http://www.nature.com/ scientificreports

Competing financial interests: The authors declare no competing financial interests.

License: This work is licensed under a Creative Commons

Attribution-NonCommercial-NoDerivs 3.0 Unported License. To view a copy of this license, visit http://creativecommons.org/licenses/by-nc-nd/3.0/

How to cite this article: Chen, S., Hung, W., Wang, P., Paul, C. \& Konstantopoulos, K Mesothelin Binding to CA125/MUC16 Promotes Pancreatic Cancer Cell Motility and Invasion via MMP-7 Activation. Sci. Rep. 3, 1870; DOI:10.1038/srep01870 (2013). 